\title{
JUVENTUDE E ACESSO DIGITAL: REFLEXÕES SOBRE O USO DA INTERNET POR JOVENS ESTUDANTES DO MUNICÍPIO DE BELÉM
}

\author{
Mateus Souza dos Santos ${ }^{1}$ \\ Lucia Isabel da Conceição Silva ${ }^{2}$ \\ Tatiene Germano Reis Nunes ${ }^{3}$
}

Resumo: A internet configura-se como um dos principais meios de circulação de informação e de comunicação entre a sociedade. Contudo, nem todas as pessoas têm acesso à realidade virtual. $\mathrm{O}$ presente estudo tem por objetivo analisar o acesso e a inclusão digital de jovens estudantes de escolas públicas do município de Belém do Pará, destacando as relações que eles estabelecem com a internet. A pesquisa foi realizada em 10 escolas públicas deste município, possibilitando a composição de uma amostra aleatória de 658 jovens de ambos os sexos, com idades entre 14 e 24 anos. O instrumento utilizado foi o Questionário Juventude Brasileira II, que é constituído de 77 questões. Os resultados mostraram um paradoxo entre o uso da internet pelos jovens e o contexto escolar, uma vez que $85 \%$ dos participantes afirmaram que não têm acesso à internet na escola, mas que a usam para fazer seus trabalhos escolares. Conclui-se que a exclusão digital é um elemento evidente principalmente na escola. Isso reflete um contexto maior de precarização da educação pública, uma vez que não estão disponíveis aos jovens um conjunto de estruturas necessárias à sua plena formação, tal como elementos referentes às tecnologias digitais.

Palavras-chave: Juventude. Acesso e inclusão digital. Exclusão digital. Internet.

\section{ACCESS AND DIGITAL INCLUSION IN YOUTH AND ADOLESCENCE: THE USE OF THE INTERNET BY STUDENTS OF PUBLIC SCHOOLS OF THE MUNICIPALITY OF BELÉM DO PARÁ}

\begin{abstract}
The Internet is one of the main means of circulating information and communication between society. However, not all people have access to virtual reality. This study aims to analyze the access and digital inclusion of young students from public schools in the city of Belém do Pará, highlighting the relationships they establish with the Internet. The research was carried out in 10 public schools of this municipality, making possible the composition of a random sample of 658 youngsters of both sexes, aged between 14 and 24 years. The instrument used was the Brazilian Youth Questionnaire II, which consists of 77 questions. The results showed a paradox between the use of the Internet by young people and the school context, since $85 \%$ of participants people stated that they do not have access to the internet at school, but that they use it to do their school work. We conclude that digital exclusion is an evident element, especially in school. This reflects a larger context of precariousness of public education, since a set of structures necessary
\end{abstract}

\footnotetext{
${ }^{1}$ Universidade Federal do Pará.

${ }^{2}$ Universidade Federal do Pará.

${ }^{3}$ Universidade Federal do Pará.
}

$$
\begin{array}{lll}
\text { v. } 20 \text { n. } 44 \quad \text { p. } 65-85 & \text { set/dez. } 2018
\end{array}
$$


for their full training, such as elements relating to digital technologies, are not available to young people.

Keywords: Youth. Access and digital inclusion. Digital exclusion. Internet

\section{INTRODUÇÃO: O SURGIMENTO DA INTERNET: DO MONOPÓLIO À SOCIALIZAÇÃO}

Caracterizar a contemporaneidade traduz-se num processo complexo que implica analises históricas das especificidades políticas, econômicas, sociais e culturais da humanidade. Nesse sentido, descrever a constituição da internet é narrar um tempo delineado por muitos avanços tecnológicos, fundamentados, principalmente, em constantes disputas políticas (ALBACH, 2012).

De certo, a configuração da internet tem sido uma obra em constante mutação que exemplifica a magnitude do intelectualismo humano, encontrando suas bases históricas em um conjunto de computadores e conexões, não muito sofisticados, mas que ao longo dos anos evoluíram e se transformaram nas tecnologias que possuímos nos dias atuais, nos transformando, portanto, em uma civilização capaz de produzir e socializar uma densa quantidade de informações.

A origem da internet se remonta aos anos 60, no auge da guerra fria, com o surgimento da ARPAnet, criada pelo Departamento de Defesa dos Estados Unidos da América (EUA). A ARPAnet surgiu para demonstrar superioridade científica e técnica que os EUA possuíam em relação à União Soviética (URSS). A princípio, tal tecnologia ligaria universidades, centros de pesquisas com fins militares e indústrias bélicas, por meio de um programa que permitiria a vários computadores, destas instituições, se comunicarem de forma online (ALBACH, 2012; MONTEIRO, 2001).

De acordo com Monteiro (2001),

Um grupo de programadores e engenheiros eletrônicos, contratados pelo Departamento de Defesa dos Estados Unidos, desenvolveu o conceito de uma rede sem nenhum controle central, por onde as mensagens passariam divididas em pequenas partes, que foram chamadas de "pacotes". Assim, as informações seriam transmitidas com rapidez, flexibilidade e tolerância a erros, em uma rede onde cada computador seria apenas um ponto (ou "nó") que, se impossibilitado de operar, não interromperia o fluxo das informações (MONTEIRO, 2001, p. 27). 
A partir dos anos 80, além de interligar laboratórios e universidades dos EUA, tal projeto norte-americano chegou a outros países, passando a ser conhecido como Internet. No final desta mesma década, a internet passou a ser conhecida com uma eficiente ferramenta para a comunicação mundial, embora ainda estivesse restrita somente ao alcance do meio acadêmico. Em 1991, com o surgimento da World Wide Web (WWW), passaram a trafegar pela rede, além de textos, os primeiros desenhos.

Desenvolvida no início da década de 1990 pelo cientista inglês Tim Berners-Lee nos laboratórios do CERN (Conselho Europeu para Pesquisa Nuclear), na Suíça, a World Wide Web nasceu da necessidade de compartilhar dados entre os membros dos diversos projetos de pesquisa em andamento no CERN. Ela foi concebida como uma ferramenta de troca de informações mais amigável que as interfaces "somente-texto" então utilizadas. Baseado no conceito de hipertexto, Tim desenvolveu uma linguagem de programação (chamada HTML, ou Hyper Text Markup Language) que permitia ao usuário - utilizando um mouse e um software chamado "browser" (navegador), desenvolvido especialmente com esta finalidade - acessar diversas informações de modo não-linear, indo de um documento (fosse ele texto, imagem ou som) a outro através de ligações entre eles, mesmo que estivessem em computadores remotos (MONTEIRO, 2001, p.29).

\title{
Torna-se importante distinguir a Internet da WWW
}

\begin{abstract}
A internet e a WWW ou World Wide Web (que quer dizer algo como "teia de alcance mundial", em inglês) não são sinônimos, embora freqüentemente utilizemos esses termos como tal. Na realidade, a WWW é um espaço que permite a troca de informações multimídia (texto, som, gráficos e vídeo) através da estrutura da internet. É uma das formas de utilização da Rede, assim como o e-mail (correio eletrônico), o FTP (File TransferProtocol) ou outros menos conhecidos atualmente (MONTEIRO, 2001, p. 29).
\end{abstract}

Assim sendo, a partir dos anos 90, os programas para navegação na Internet já permitiam o uso de links e faziam o reconhecimento de imagens e gráficos. Também neste mesmo período, de acordo com Oliveira (2008), deuse início a grande expansão da Internet no âmbito comercial.

Nas palavras de Albach (2012, p.34), a internet, juntamente com outros meios de comunicação, inaugura 
uma nova forma de interação das pessoas, de veiculação de informações que teve início com as mídias clássicas (televisão, rádio), interligadas com os processos de comunicação (como o telefone), que alteraram as formas de relação entre as pessoas aproximando as fronteiras. Ou seja, não é a internet sozinha que modificou a sociedade, mas um conjunto de fatores que culminou popularização do computador e da internet.

Até o final do século XX, a socialização de informações nunca esteve ao alcance do cidadão comum, pois exigia grandes recursos financeiros (necessários para o acesso às tecnologias de reprodução e difusão, como parques gráficos e emissoras de rádio ou televisão), essa possibilidade estava restrita a um grupo elitizado que detinha o controle dos veículos de massa. (MONTEIRO, 2011)

Além disso, por serem provenientes de poucas fontes, essas informações podiam ser facilmente controladas. Entretanto, com o advento da internet esse quadro se altera, uma vez que as informações passaram a ser disponibilizadas em diversas fontes. Além disso, o custo para divulgar e acessar informações é reduzido, o que aumenta a possibilidade de mais pessoas se envolverem no processo de socialização das notícias (MONTEIRO, 2011).

A história da internet é marcada por muitos acontecimentos que são difíceis de serem sintetizados em poucas linhas ${ }^{4}$, entretanto, os fatos que descrevemos aqui demonstram as modificações que ela sofreu, uma vez que inicialmente a internet obedecia a interesses isolados e que, após um processo de muitas discussões, se ampliaria para outros âmbitos sociais.

Contudo, apesar da maior abrangência que a internet ganhou ao longo dos anos, percebe-se que nem todas as pessoas estão incluídas no mundo virtual, o que as exclui de terem acesso a diversos tipos de informações. Além do mais, não podemos esquecer que "utilizar a internet exige diversas capacidades (como compreensão de textos complexos, comunicação por escrito, operação de computadores e softwares, entre outras), que exigem um grau de instrução relativamente elevado" (MONTEIRO, 2011, p 34).

Desse modo, torna-se imprescindível a inclusão digital de todas as pessoas, para que elas possam ter acesso aos diversos benefícios que a internet

4 Estudos que discutem de forma mais aprofundada o surgimento da internet: Monteiro (2011), Carvalho (2006), Albach (2012). 
nos proporciona. Inclusão digital não significa disponibilizar para uma pessoa um computador, sendo que outros elementos mais subjetivos também são necessários para o uso consciente da internet.

\section{INCLUSÃO, ACESSO DIGITAL E EDUCAÇÃO}

O acesso aos conhecimentos produzidos ao longo da história pelo homem é indispensável para que possamos nos constituir enquanto seres humanos. Como nos afirma Brandão (2015), somos "um eu chamado nós”, na medida em que nossas concepções estão permeadas por ideias que foram construídas historicamente pela humanidade. Quando chegamos neste mundo já existiam instrumentos, escritos, em suma, saberes que foram produzidos por gerações passadas. Contudo, nem todas as pessoas são incluídas nesse processo de socialização das produções humanas, o que limita o seu campo de conhecimento e as isola de um mundo marcado pela diversidade.

Assim, o isolamento diante do conhecimento pode se constituir como um elemento que prejudica o desenvolvimento do sujeito. De acordo com Leite e Nunes (2009), a inclusão e a exclusão não são temas da atualidade:

O tema da inclusão e o de sua contrapartida - a exclusão - tem feito parte da história da humanidade, entremeado por práticas discursivas que explicam o pertencimento ou não de determinadas instituições, associações, grupos e indivíduos nas esferas de poder e de prestígio (LEITE; NUNES, 2009, p. 200).

Incluir é respeitar a diversidade, reconhecendo as especificidades de cada pessoa. Incluir é um novo modo de encarar a diferença, é negar a homogeneização e afirmar a heterogeneidade como algo inerente a sociedade.

Conceito polissêmico, decorrente da complexidade das relações humanas, a inclusão é processual e contraditória, construída no diálogo e na necessidade de grupos sociais conviverem com as diferenças. Trata-se de uma referência de cidadania que visa garantir a todas as pessoas condições objetivas de fruição de bens naturais, sociais e culturais, frutos da produção coletiva, mas que se encontram distribuídos de forma muito desigual (LEITE; NUNES, 2009, p. 200, grifo nosso).

A inclusão é um movimento educacional, mas também social e político que vem defender o direito de todos os indivíduos 
participarem, de uma forma consciente e responsável, na sociedade de que fazem parte, e de serem aceites e respeitados naquilo que os diferencia dos outros (FREIRE, 2008, p.5).

No Brasil as discussões a respeito da inclusão estão muito presentes nas escolas, devido o direito que todos os alunos têm, independentemente de suas especificidades, a uma escolarização gratuita e de qualidade. Este é um princípio constitucional (BRASIL, 1988) e que também está presente no Estatuto da Criança e do Adolescente (ECA) (BRASIL, 1990) e na Lei de Diretrizes e Bases da Educação Nacional (LDB) (BRASIL, 1996):

A educação, dever da família e do Estado, inspirada nos princípios de liberdade e nos ideais de solidariedade humana, tem por finalidade o pleno desenvolvimento do educando, seu preparo para o exercício cidadania e sua qualificação para o trabalho (BRASIL, 1996).

O artigo $4^{\circ}(\S 3)$ da LDB prevê o atendimento educacional especializado gratuito aos alunos com necessidades especiais, preferencialmente na rede regular de ensino. Assim sendo, ao assumir a educação inclusiva como paradigma de ação Estatal na área educacional, o Brasil optou por parâmetros de conduta dos sistemas de ensino com implicações conceituais e operativas, tais como:

Aprender é uma ação humana em cuja centralidade está o aluno; Adaptar o conteúdo escolar é ação do próprio aluno no âmbito do processo de autorregulação; Modular a assimilação dos conhecimentos é processo dependente das limitações e possibilidades do aluno; reconhecer e valorizar as diferenças é o primeiro passo para a escola comum recriar suas práticas pedagógicas; trabalhar com uma gama variada de atividades é o grande desafio do professor da educação especial; aferir programas no campo da aprendizagem e, não, conferir quantidade de conteúdos programáticos aprendidos, é a forma adequada de proceder a avaliação dos alunos com deficiência. (CARNEIRO, 2013, p. 73).

Nessa perspectiva, o processo educativo deve se adequar às especificidades do aluno, buscando além de sua permanência na escola, o seu máximo desenvolvimento. Isto exige amplas mudanças organizacionais e funcionais em diferentes níveis do sistema educativo: mudanças na articulação dos diferentes agentes educativos; mudanças na gestão da sala de aula e do currículo; e mudanças do próprio processo de ensino-aprendizagem. Todas 
essas exigências que compõem a educação inclusiva podem originar resistências e medos, o que dificulta a materialização de tais princípios (FREIRE, 2008).

Em linhas opostas à inclusão, emerge a exclusão que diz respeito à convivência de situações nas quais um grupo de pessoas não é incorporado ao sistema básico de relações e proteções sociais e outros, já incorporados anteriormente, no momento, encontram-se excluídos (LEITE; NUNES, 2009). Alvino-Borba e Mata-Lima (2011) destacam que alguns dos fatores clássicos de exclusão (fome, pobreza e desemprego), apesar de antigos, ainda permanecem em evidência na sociedade contemporânea.

Todo esse processo de negação de direitos na atualidade é fortalecido por um sistema econômico que prega o acúmulo de riquezas nas mãos de poucos e que gera fortes desigualdades sociais. Para Tumulo (2012) a finalidade do capitalismo não está ancorada nas necessidades humanas e, portanto, na emancipação dos sujeitos, mas em dois grandes objetivos:

necessidade de diminuição do valor das mercadorias por causa da concorrência intercapitalista e, 2. necessidade de diminuição do valor da força de trabalho que redunda na produção e exploração da mais-valia relativa e, por conseguinte, no aumento no grau de exploração da força de trabalho (TUMULO, 2012, p.159).

Logo, a exclusão se dá no mundo do trabalho, na educação, em síntese, em todos os âmbitos sociais. No que tange ao foco deste estudo (o uso de internet por jovens) o acesso ao mundo virtual também se configura como uma espécie de exclusão que afeta diversos seguimentos sociais e os jovens.

Há, portanto, a necessidade de inserção dos sujeitos em dinâmicas tecnológicas que definem a época atual, como integrantes de uma sociedade mobilizada pela informação circundante na internet e presente em boa parte dos campos de vivência do indivíduo contemporâneo. Logo, este cenário impulsiona a uma participação nesses processos, pois, do contrário, este sujeito poderá se encontrar marginalizado de sua própria realidade.

A inclusão e exclusão digital são foco de diversos campos sociais que estudam esses fenômenos como parte de uma problemática mais ampla, que envolve a segregação, a desigualdade e a inequidade social. Compreende-se que estes três últimos elementos dificultam o desenvolvimento de uma sociedade democrática, haja vista que negam ao sujeito o direito de participar ativamente de diferentes meios de trocas e possibilidades de informação. 
Para Almeida e Paula (2005), a inclusão digital, em primeiro lugar, tem relação com o acesso às informações que estão em diversos meios digitais e que necessitam de ferramentas materiais para serem acessadas. Desse modo, o econômico - as garantias materiais - é concebido como condição imprescindível no processo de inclusão no universo digital, sendo que a distribuição desigual de renda pode estar relacionada com a exclusão digital.

A pobreza limita o acesso à internet e se converte num fator de exclusão. Assim, pessoas de baixo nível econômico podem não encontram possibilidades do contato com a internet, ficando excluídas digitalmente. Este é ponto de partida da noção de exclusão digital, sendo conceituada como um estado no qual um indivíduo é privado da utilização das tecnologias de informação (ALMEIDA; PAULA, 2005).

Os valores econômicos são de suma importância para a democratização da internet, entretanto não são os únicos, dado que ter ou não acesso ao estrutural é somente uma das variáveis que influenciam, mas não a única. Porquanto, abrangem também as habilidades necessárias para a assimilação do conhecimento, as capacidades para sua utilização no desenvolvimento da vida, além das diversas situações que envolvem aos indivíduos. As problemáticas em torno do tema não se resolveriam, por exemplo, com a distribuição de uma grande quantidade de computadores para as camadas em condição de pobreza.

$\mathrm{O}$ assunto tem relação com o analfabetismo, a formação escolar, as diferenças geracionais, e até a falta de interesse e significados. Segundo Almeida e Paula (2005, p. 59),

Já aquelas pessoas que, apesar de terem uma condição financeira favorável e alguma formação escolar, são resistentes às mudanças e não se envolvem com as novas tecnologias, ficam desatualizadas e tornam-se membros da sociedade da exclusão digital e consequentemente da exclusão social, visto que passam a ter maiores dificuldades em conseguir empregos, desenvolver suas carreiras, realizar pesquisas escolares, etc.

Assim, a inclusão requer processos de escolarização que possam garantir a compreensão de caracteres básicos como letras e números, mas também a aprendizagem desses novos códigos linguísticos próprios da internet. Ainda mais, a focalização nas habilidades que possibilitam uma compreensão e assimilação consciente dos significados e de sua posterior utilização nos relacionamentos laborais, acadêmicos e comunitários. 
Silvia et al., (2005, p.33) destaca que

A alfabetização em informação deve criar aprendizes ao longo da
vida, pessoas capazes de encontrar, avaliar e usar informação
eficazmente, para resolver problemas ou tomar decisões. Uma
pessoa alfabetizada em informação seria aquela capaz de
identificar a necessidade de informação, organizá-la e aplicá-la na
prática, integrando-a a um corpo de conhecimentos existentes e
usando-a na solução de problemas.

A este processo de alfabetização digital tem de se acrescentar o assunto da permanência, pois entrar ao mundo virtual e ter as capacidades de se desenvolver no seu interior não é garantia da continuidade. A estratégia consistiria em gerar interesses, chamando à atenção dos sujeitos, para que eles encontrem na internet elementos significativos e úteis para suas atividades cotidianas. É uma tarefa de motivação na busca de razões para continuar o processo.

Consequentemente, a ausência das condições até ao momento mencionadas (acesso, alfabetização, formação, segurança de permanência) convertem-se numa fonte de exclusão, que marginaliza aos sujeitos, impossibilitando-os de criar, receber e compartilhar informação em prol de seu desenvolvimento social, cultural e político.

Em sua condição de cidadãos os sujeitos são portadores de direitos e deveres que funcionam como organizadores da convivência em comunidade. Contudo, percebesse a necessidade da inclusão digital como assunto político, como possibilidade de estar e agir na sociedade contemporânea. Assim, a construção de uma sociedade democrática também perpassa pelo direito que todos têm ao acesso ao conhecimento e, mais especificamente, aos saberes presentes em uma realidade virtual que a cada dia só se expande.

Assim sendo,

\begin{abstract}
A inclusão digital deveria ser fruto de uma política pública com destinação orçamentária a fim de que ações promovam a inclusão e equiparação de oportunidades a todos os cidadãos. Neste contexto, é preciso levar em conta indivíduos com baixa escolaridade, baixa renda, limitações físicas e etárias. (ALMEIDA; PAULA, 2005, p. 59).
\end{abstract}

Nessa perspectiva, após compreender a importância da inclusão digital, o presente estudo visa discutir como os jovens estudantes de escolas públicas do 
município de Belém estão se relacionando com a internet. Eles têm acesso a esta ferramenta e para quais fins eles a usam? Estas são algumas problemáticas que irão nortear as discussões em torno dos achados da pesquisa.

\section{MÉTODO: DELINEAMENTO E PARTICIPANTES}

Participaram deste estudo 658 jovens com idades entre 14 e 24 anos, de ambos os sexos, estudantes de 13 escolas públicas do município de Belém, estado do Pará. A seleção destas instituições se deu por meio de sorteio, sendo que todas as escolas públicas de Belém fizeram parte deste processo. Posteriormente, foram sorteadas as turmas compostas por jovens que iriam responder ao Questionário Juventude Brasileira III.

O número de participantes foi obtido através do calculo amostral, a partir do número total de jovens residentes dentro da faixa etária escolhida (Dados do censo 2010 - IBGE), com uma margem de erro estabelecida de $4 \%$ (BARBETTA, 2001).

Do total de participantes da pesquisa $35 \%(\mathrm{n}=230)$ eram do sexo masculino e $55,6 \%(\mathrm{n}=366)$ eram do sexo feminino, além disso, 9,4\% $(\mathrm{n}=62)$ não declararam o seu sexo.

A tabela 1 apresenta a distribuição dos jovens por faixa etária:

Tabela 01: Distribuição da amostra por faixas etárias

\begin{tabular}{cccc}
\hline Faixa etária & Frequência & $\mathbf{\%}$ & \% acumulado \\
\hline 12 a 14 anos & 149 & 23,5 & 23,5 \\
15 a 17 anos & 318 & 50,0 & 73,5 \\
18 a 20 anos & 131 & 20,5 & 94,0 \\
21 a 24 anos & 38 & 6,0 & 100,0
\end{tabular}

FONTE: Pesquisa: Entre risco e Proteção: O ser Jovem em Belém do Pará (2013).

No que tange à cor, grande parte da amostra é comporta por negros e pardos $(74 \%)$. 


\section{INSTRUMENTO}

O instrumento utilizado foi o Questionário Juventude Brasileira II (DELL'AGLIO et al., 2011) que é constituído de 77 questões, sendo algumas de múltipla escolha e outras em formato Likert de cinco pontos sobre intensidade e frequência. Esse instrumento permite coletar dados sobre aspectos relacionados à educação, à saúde, ao trabalho, a comportamentos de risco (drogas, suicídio, sexualidade, violência), a fatores de risco (violência intrafamiliar e extrafamiliar, deficiência, conflito com a lei, eventos estressores, preconceito) e a fatores protetores sociais (lazer, rede de apoio) e pessoais (espiritualidade, autoestima, autoeficácia, perspectivas para o futuro) (DELL'AGLIO, et al., 2011).

\section{PROCEDIMENTOS ÉTICOS}

Foi solicitado o Termo de Consentimento Livre e Esclarecido aos pais (para adolescentes com menos de 18 anos de idade), assim como a concordância dos próprios adolescentes em participar do estudo. Esclarecemos aos jovens que a sua participação era voluntária e que as informações pessoais seriam mantidas sob sigilo. Os participantes também tinham a possibilidade de desistir a qualquer momento da pesquisa.

\section{RESULTADOS}

Os dados sobre os principais contextos em que os jovens paraenses usam a internet estão organizados na tabela 2 .

Tabela 2: Contexto onde os jovens paraenses usam a Internet - 2013.

\begin{tabular}{ccccc}
\hline $\begin{array}{c}\text { Onde você usa } \\
\text { a Internet? }\end{array}$ & SIM & $\mathbf{\%}$ & NÃO & \% \\
\hline Em casa. & 336 & 69,1 & 150 & 30,9 \\
No trabalho. & 21 & 5,3 & 372 & 94,7 \\
Na Escola. & 61 & 15 & 347 & 85 \\
$\quad$ Na Lan & 208 & 47,8 & 227 & 52,2 \\
House/Cyber. & & & & \\
\hline
\end{tabular}


FONTE: Pesquisa: Entre risco e Proteção: O ser Jovem em Belém do Pará (2013).

Nos chama à atenção o baixo índice de uso de internet na escola, sendo que ela poderia servir de ponte entre os conhecimentos curriculares e os saberes presentes na internet.

Mesmo diante dessas dificuldades de acesso à internet no ambiente escolar, os estudantes do município de Belém afirmam que usam a internet, principalmente, para fazer trabalhos escolares. É isso que a tabela 3 apresenta:

Tabela 3: Finalidades do uso da internet por estudantes do município de Belém.

\begin{tabular}{ccccc}
\hline $\begin{array}{c}\text { Uso a internet } \\
\text { para: }\end{array}$ & SIM & $\mathbf{\%}$ & NÃO & $\mathbf{\%}$ \\
\hline $\begin{array}{c}\text { Me comunicar com as } \\
\text { pessoas (e-mail, }\end{array}$ & 493 & 88 & 66 & 11,8 \\
$\begin{array}{c}\text { Orkut, msn, etc.) } \\
\text { Baixar músicas, jogos, }\end{array}$ & 363 & 55,2 & 157 & 30,2 \\
$\quad$ filmes. & & & & \\
Fazer trabalhos da & 493 & 87,4 & 71 & 12,6 \\
$\quad$ escola. & & & & \\
Navegar em sites de & 319 & 62,8 & 188 & 37 \\
meu interesse. & & & & \\
Fazer/Escrever blogs. & 75 & 17 & 366 & 83 \\
$\quad$ Jogar. & 275 & 56,2 & 213 & 43,6 \\
Comprar coisas. & 86 & 19,2 & 362 & 80,8 \\
Outras atividades. & 34 & 8,0 & 392 & 92 \\
\hline FONTE: Pesquis: Entre
\end{tabular}
Pará (2013).

Os dados organizados na tabela 4 mostram que os jovens costumam usar a internet durante vários dias da semana, o que a torna parte integrante do cotidiano desses sujeitos: 
Tabela 4: Frequência de uso da internet durante os dias da semana.

\begin{tabular}{ccc}
\hline Uso Durante os Dias da Semana & N & \% \\
\hline Não utilizo. & 33 & 5,6 \\
Uma ou duas vezes por mês. & 78 & 13,2 \\
Apenas os finais de semana. & 95 & 16,1 \\
De uma a duas vezes na semana. & 80 & 13,6 \\
Entre três e cinco dias na semana. & 97 & 16,4 \\
Todos os dias. & 205 & 34,7 \\
Total. & 590 & 100,0 \\
\hline
\end{tabular}

FONTE: Pesquisa: Entre risco e Proteção: O ser Jovem em Belém do Pará (2013).

A tabela 5 descreve o tempo em que os jovens ficam conectados à internet:

Tabela 5: Tempo de uso da internet por jovens de Belém do Pará

\begin{tabular}{ccc}
\hline Tempo de uso diário & $\mathbf{N}$ & $\mathbf{\%}$ \\
\hline Não me conecto a Internet. & 25 & 4,2 \\
Menos de meia hora. & 32 & 5,4 \\
De meia a uma hora. & 180 & 30,4 \\
De uma a três horas. & 179 & 30,2 \\
De três horas a cinco horas. & 68 & 11,5 \\
Mais de cinco horas. & 105 & 17,7 \\
Total. & 592 & 100,0 \\
\hline
\end{tabular}

FONTE: Pesquisa: Entre risco e Proteção: O ser Jovem em Belém do Pará (2013).

\section{DISCUSSÃO}

De acordo com a Pesquisa Brasileira de Mídia realizada em 2015 (BRASIL, 2015), a internet é o terceiro veículo de comunicação mais utilizado no Brasil (42\%), ficando atrás da televisão (93\%) e, por uma mínima diferença, do rádio (46\%). Além disso, a pesquisa também constatou que, apesar da relevância social que a internet possui, ainda é alto o percentual de entrevistados que não a utilizam (51\%). 
No Brasil, as características sociodemográficas da população têm um grande impacto no uso da internet, principalmente se comparada aos outros meios de comunicação. Renda e escolaridade criam um hiato digital entre quem é um cidadão conectado e quem não é. Já os elementos geracionais ou etários mostram que os jovens são usuários mais intensos das novas mídias. No que tange ao púbico jovem, a pesquisa supracitada mostrou que $65 \%$ dos jovens com até 25 anos acessam internet todos os dias (BRASIL, 2015).

Os dados da nossa pesquisa mostram que 445 jovens (83,3\%) têm acesso à internet, 25 jovens $(4,2 \%)$ não se conectam a internet e que 205 jovens $(34,7$ \%) a utilizam todos os dias.

Além disso, os dados organizados na tabela 2 mostram que 347 jovens, o que corresponde a $85 \%$ da amostra, não utilizam a internet na escola. Isso demonstra que as novas tecnologias estão caminhando de forma muito lenta para dentro dos muros das escolas. Talvez este problema ocorra por falta de estrutura física nas instituições (laboratórios de informática bem equipados e que estejam à disposição dos alunos), escassez de profissionais qualificados, em suma, de políticas públicas que favoreçam o uso de novas tecnologias nas escolas.

Para Albach (2012), no atual contexto social, os conhecimentos produzidos pela humanidade não se encontram apenas dentro de livros, eles estão disseminados numa diversidade de textos e formas de acesso. Assim sendo, embora a juventude mantenha um estreito laço com o uso da internet, isso é pouco evidenciado ou tratado pela escola.

Ainda sobre o uso da internet, Masseto (2010) destaca os seus grandes benefícios para o processo de aprendizagem:

Sem dúvida, a Internet é um grande recurso de aprendizagem múltipla; aprende-se a ler, buscar informações, pesquisar, comparar dados, analisá-los, criticá-los, organizá-los. Com a Internet podemos desenvolver habilidades para explorar esse novo recurso tecnológico; desenvolver nossa criatividade; discutir valores éticos, políticos e sociais na consideração dos fatos e fenômenos que chegam ao nosso conhecimento de todas as partes do mundo (MASSETO, 2010, p. 149).

Assim sendo, a escola deveria ser mediadora entre alunos e internet, para que eles possam usar esta ferramenta de forma crítica e consciente, favorecendo, portanto, o seu desenvolvimento. É importante destacar que as 
escolas que fizeram parte deste estudo são de bairros periféricos do município de Belém e atendem a estudantes de classe baixa, o que evidencia, mais uma vez, a grande desigualdade social que afeta o nosso país. São estudantes pobres que não têm em suas escolas acesso a esta tecnologia que se tornou tão importante para o processo de socialização do saber.

Um paradoxo que nos instigou foi o fato de os jovens afirmarem que não utilizam a internet na escola, mas que a usam para fazer seus trabalhos escolares $(\mathrm{n}=493$ [87,4\%]). Em outras pesquisas (BRASIL, 2015; LEITE; NUNES, 2007; MIRANDA et al., 2013) a internet também aparece como um instrumento que auxilia os alunos na realização de trabalhos escolares bem como um meio para estudar e aprender novos conhecimentos.

Para Albach (2012), os textos que estão disponíveis na internet podem dialogar com a escola, na medida em que a internet - apesar de possuir como característica primordial a diversidade - dispõem de materiais que podem servir de instrumento para reflexões no interior das instituições de ensino.

A internet não anula a realização de pesquisas em outras fontes como, por exemplo, as bibliotecas, uma vez que os conhecimentos encontrados pelos alunos podem ser complementares ou até mesmo discordantes, cabendo a ele, com o auxílio de um professor, selecionar os materiais que serão usados. A pesquisa escolar, portanto, "seria uma prática pedagógica com o papel de fazer o aluno buscar algo, aprofundar-se num assunto determinado pelo professor para extrapolar as questões levantadas em sala de aula" (ALBACH, 2012, p.14).

Desse modo, ao utilizar a internet para realizar um trabalho escolar o aluno dispõe de um universo de informações que vão lhe auxiliar no desenvolvimento de suas atividades escolares e na ampliação dos seus conhecimentos. Para os professores, de acordo com Oliveira (2008), a pesquisa no ambiente escolar é uma prática pedagógica que leva o aluno à curiosidade, isto é, os conduz a ir além do que se constrói em sala de aula, possibilitando o desenvolvimento da capacidade de análise e crítica das informações encontradas, da criatividade, da autonomia em aprender e da elaboração própria.

Moro e Estabel (2004) comentam que a pesquisa escolar deveria se caracterizar como uma atividade sistematizada, um processo formal, que visa encontrar respostas para questões propostas pelo professor ou pela própria turma. Assim sendo, por conta da grande variedade de informações que existem na internet, o aluno deve sempre contar com o auxílio de um profissional 
capacitado, principalmente pelo professor. Aqui chegamos a outro entrave que dificulta a utilização da internet nas escolas e que já foi objeto de estudo de outros autores $^{5}$ : A internet como um desafio para os educadores. Entretanto, não é de nosso objetivo principal nos aprofundarmos nesta discussão.

Os dados organizados na tabela 3 também mostram que os jovens paraenses costumam usar a internet como um meio para interagir com outras pessoas, posto que 493 jovens (88 \%) afirmaram usar a internet para se comunicar com as pessoas.

De acordo com Coll e Monereo (2010), graças à interligação entre diferentes computadores digitais e à internet chegamos, assim, strictu sensu, a uma sociedade que comporta novas formas de trabalhar, de se comunicar, de se relacionar, de aprender, de pensar e, em suma, de viver, que poderíamos definir como um novo estágio de desenvolvimento das sociedades humanas, caracterizado pela capacidade de seus membros para obter e compartilhar qualquer quantidade de informação de maneira praticamente instantânea, a partir de qualquer lugar e na forma preferida, e com custo muito baixo.

Nesse sentido, os ambientes virtuais, principalmente, as redes sociais (como o Facebook, WhatsApp, Instagram e Twitter) tornam-se espaços de fácil acesso e de constantes interações (publicações, comentários, chats, etc). A internet se converte, então, em um espaço de socialização de uma infinidade de imaginários, saberes, gostos e visões de mundo, visto que ela possibilita a expansão em poucos segundos de pensamentos e estados emocionais materializados nos códigos próprios da rede.

Os dados da tabela 4 mostram que boa parte dos jovens que usam a internet todos os dias $(\mathrm{n}=205$ [34,7\%]). Já a tabela 5 indica que há uma quantidade significativa de jovens que passa mais de cinco horas conectado na rede $(\mathrm{n}=105[17,7 \%])$. Como vimos durante o desenvolvimento deste trabalho, a internet ocupa um papel central no desenvolvimento da nossa sociedade, entretanto o seu uso abusivo pode trazer problemas à saúde mental dos sujeitos, sendo de grande relevância que os jovens recebam orientações de como devemos usá-la (FORTIM; ARAÚJO, 2013).

Fortim (2013) destaca alguns problemas que o uso demasiado de internet pode acarretar:

\footnotetext{
${ }^{5}$ Verificar Abreu et al., (2003).
} 
As consequências negativas estão relacionadas a prejuízos no trabalho, como faltas, baixo rendimento, colocando em risco de demissão ou em situações constrangedoras pela incapacidade de controlar o uso. [...] Ainda entre as consequências negativas, estão os conflitos familiares. $\mathrm{O}$ uso excessivo faz com que o usuário descuide de relacionamentos familiares importantes, tais como o casamento, relação entre pais e filhos, relacionamentos com amigos que não os virtuais (FORTIM; ARAÚJO, 2013, p. 295).

Assim sendo, as políticas de inclusão digital também devem ter em suas linhas de discussão a orientação do modo como os jovens podem usar a internet e das consequências que o uso não adequado pode trazer.

\section{CONSIDERAÇÕES FINAIS}

Os achados deste estudo possibilitaram uma visão das relações existentes entre a juventude paraense e a internet. Após analisar os principais usos que os jovens fazem da internet (realizar tarefas escolares e interagir com outras pessoas) se percebe uma notável contradição entre as práticas pedagógicas que se estabelecem dentro das escolas e as estruturas materiais disponíveis para que essas práticas possam ser desenvolvidas no âmbito da própria instituição. Os jovens buscam em outros espaços a oportunidade de acesso à internet, principalmente em casa ou em lan houses.

Do mesmo modo, confirma-se o contato cotidiano dos jovens com a internet, caracterizado pela frequência constante e a quantidade significativa de tempo em que eles passam conectados. Por outro lado, notamos que a exclusão digital é um elemento evidente nas escolas públicas, o que pode estar relacionado evidencia à falta de projetos e de políticas de inclusão digital neste contexto.

Este fato, por sua vez, extrapola para uma situação estrutural mais ampla de segregação e desigualdade social no Brasil, que nos remete à urgência de materializar propostas em torno do tema, isto é, de políticas públicas que favoreçam a construção de uma escola mais democrática.

Esperamos que esses debates sobre a internet como direito da juventude possam se converter em mudanças estruturais que favoreçam o desenvolvimento destes sujeitos e que fomentem debates no âmbito social. 


\section{REFERENNCIAS}

ALBACH, Juliana Santos. Os usos que os jovens fazem da internet: relações com a escola. 2012. 331 f. Dissertação (Mestrado) - Programa de Pós-graduação em Educação, Universidade de São Paulo, São Paulo, 2012.

ALVINO-BORBA, Andreilcy; MATA-LIMA, Herlander. Exclusão e inclusão social nas sociedades modernas: um olhar sobre a situação em Portugal e na União Européia. Serviço Social ; Sociedade, v. 106, p.219-240, abr. 2011. Disponível em: <http://www.scielo.br/pdf/sssoc/n106/n106a03.pdf〉. Acesso em: 04 jun. 2015.

ALMEIDA, Lúlia Bilati de et al. O retrato da exclusão digital na realidade brasileira. Revista de Gestão da Tecnologia e Sistemas de Informação, Rio de Janeiro, v. 2, n. 01, p. 55-67, mar. 2004. Disponível em:

$\langle$ http://www.scielo.br/pdf/jistm/v2n1/05.pdf >. Acesso em: 05 jun. 2015.

BRASIL. Presidência da República. Secretaria de Comunicação Social.

Pesquisa brasileira de mídia 2015: hábitos de consumo de mídia pela população brasileira. - Brasília: Secom, 2014.

BRONFENBRENNER, Urie. A ecologia do desenvolvimento

Humano: Experimentos Naturais e Planejados. Porto Alegre: Artes Médicas, 1996. Tradução de: Maria Adriana Veríssimo.

CARNEIRO, M. A. LDB Fácil, Leitura Crítico-Compreensiva Artigo a Artigo. 20. Ed. Petrópolis - RJ: Editora Vozes, p.581, 2012.

CARVALHO, Marcelo Sávio Revoredo Menezes de. A trajetória da Internet no Brasil: do surgimento das redes de computadores à instituição dos mecanismos de governança. 2006. 239 f. Dissertação (Mestrado), Universidade Federal do Rio de Janeiro, Rio de Janeiro, 2006. Disponível em:

<http://www.socid.org.br/files/trajetoria_internet.pdf>. Acesso em: 04 jun. 2015.

COLL, César; MONEREO, Carles. Educação e aprendizagem no século XXI. In: COLL, César; MONEREO, Carles. Psicologia da educação virtual: aprender e ensinar com as tecnologias da informação e da comunicação. 67897654567. ed. Porto Alegre: Artmed, 2010. p. 15-46. Tradução de Naila Freitas; Consultoria, supervisão e revisão técnica: Milena Silva. 
DELL'AGLIO, D. D.; KOLLER, S. H.; CERQUEIRA, S., E. ; COLAÇO, V. F. R. Revisando o Questionário da Juventude Brasileira: Uma nova Proposta. In: DELL'AGLIO, Débora D.; KOLLER, Sílvia Helena. (Org.). Adolescência e Juventude: Vulnerabilidade e Contextos de Proteção. 1 ed. São Paulo: Casa do Psicólogo, 2011, p. 259-270.

FREIRE, Sofia. Um olhar sobre a inclusão. Revista da Educação, v. 16, n. 1, p.5-20, 2008. Disponível em:

<http://repositorio.ul.pt/bitstream/10451/5299/1/Um olhar sobre a Inclusão.pdf〉. Acesso em: 04 jun. 2015.

FORTIM, Ivelise; ARAUJO, Ceres Alves de. Aspectos psicológicos do uso patológico de internet. Academia Paulista de Psicologia, São Paulo, v. 33, n. 85, p.292-311, 2013. Disponível em:

<http://pepsic.bvsalud.org/pdf/bapp/v33n2/a07.pdf>. Acesso em: 08 jun. 2015.

LEITE, Ana Maria Alexandre; NUNES, Maria Fernanda. Juventudes e Inclusão Digital: reflexões sobre acesso e uso do computador e da internet pelos jovens. In: ABRAMOVAY, Miriam; ANDRADE, Eliane Ribeiro; ESTEVES, Luiz Carlos Gil (Org.). Juventudes: outros olhares sobre a diversidade. Brasília: MEC/UNESCO, 2007. p. 197-226.

MASETTO, Marcos. Aula com apoio de tecnologia de informação e comunicação para as atividades presenciais. In: MASETTO, Marcos. O professor na hora da verdade: a prática docente no ensino superior. São Paulo: Avercamp, 2010. p. 139-155.

MAIA, R. C.; SILVA, L. I. C.; GERMANO, T.; SANTOS, M. S. Violência Intrafamiliar como fator de risco: exposição à violência física em jovens paraenses. In: I Seminário Internacional de Políticas Públicas educacionais, cultura e formação de professores, 2014, Belém. I Seminário Internacional de Políticas Públicas educacionais, cultura e formação de professores, 2014. v. único. p. 1-10.

Nunes, T. G. R.; Pontes, F. A. R.; Silva, L. I. C.; Dell'Aglio, Débora Dalbosco. Fatores de risco e proteção na escola: Reprovação e expectativas de futuro de jovens paraenses. Revista Psicologia Escolar e Educacional, v. 18, p. 203-210, 2014. Disponível em: <http://www.scielo.br/pdf/pee/v18n2/1413-8557-pee-1802-0203.pdf>. Acesso em: 09 jun. 2015. 
MIRANDA, Luciana Lobo et al. Consumo e produção midiática por estudantes de escolas públicas de Fortaleza/Brasil. Interacções, Fortaleza, v. 9, n. 26, p.169190, dez. 2013. Disponível em:

<http://revistas.rcaap.pt/interaccoes/article/view/3363>. Acesso em: 05 jun. 2015.

MONTEIRO, Luís. A internet como meio de comunicação: possibilidades e limitações. In: XXIV Congresso Brasileiro da Comunicação, 2001, Campo Grande, p. 27 - 37. Disponível em:

<http://www.portcom.intercom.org.br/navegacaoDetalhe.php? id=41856>. Acesso em: 04 jun. 2015.

MORO, Eliane Lourdes da Silva; ESTABEL, Lizandra Brasil. A pesquisa escolar propiciando a integração dos atores - alunos, educadores e bibliotecários - irradiando o benefício coletivo e a cidadania em um ambiente de aprendizagem mediado por computador. Informática na Educação, v. 7 , p.51-61, 2004. Disponível em: <http://www.cinted.ufrgs.br/ciclo3/af/03apesquisa.pdf $>$. Acesso em: 06 jun. 2015.

MOURA, Gisely J. F.; SILVA, L. I. C.; NUNES, T. G. R.; PUGET, S. G. Juventude e violência no espaço escolar: caracterizando agressores e tipos de violência. In: I Seminário Internacional de Políticas Públicas educacionais, cultura e formação de professores, 2014, Belém. XII Seminário Internacional de Políticas Públicas educacionais, currículo e formação de professores e XII Seminário Nacional de políticas educacionais e currículo, 2014. v. único. p. 0110.

OLIVEIRA, Carla Ariella de. A Pesquisa Escolar em Tempos de Internet: Reflexões sobre essa Prática Pedagógica. 2008. 131 f. Dissertação (Mestrado) - Universidade Federal do Paraná, Setor de Educação, Curitiba, 2008. Disponível em: 〈http://www.ppge.ufpr.br/teses/M08_oliveira.pdf〉. Acesso em: 04 jun. 2015.

SILVA, Helena et al. Inclusão digital e educação para a competência informacional: uma questão de ética e cidadania.Ciência da Informação, Brasília, v. 34, n. 01, p.28-36, jan. 2005. Disponível em: <http://www.scielo.br/pdf/ci/v34n1/a04v34n1>. Acesso em: 05 jun. 2015. 
SILVA, Lúcia Isabel. Entre risco e proteção: o ser jovem em Belém do Pará. Relatório Final de pesquisa. UFPA. ICED. 2013.

SILVA, K. M.; SILVA, L. I. Juventude e uso de drogas: considerações sobre a dinâmica familiar. In: II Colóquio de pesquisa em educação, cultura e sociedade, 2013, Belém. II Colóquio de pesquisa em educação, cultura e sociedade, 2013. v. único.

TUMOLO, Paulo Sergio. Trabalho, ciência e reprodução do capital. In: BERTOLO, Edna; MOREIRA, Luciano Accioly Lemos; JIMENEZ, Susana (Org.). Trabalho, Educação e Formação Humana: Frente à necessidade histórica da revolução. São Paulo: Instituto Lukács, 2013. p. 157-162.

Recebido em 20 de abril de 2018. Aprovado em 21 de agosto de 2018. 